\title{
LA ACCIÓN DE LESIVIDAD EN LA LEY N³460 DE PROCEDIMIENTOS ADMINISTRATIVOS DE CORRIENTES, EN EL CONTENCIOSO ADMINISTRATIVO-LEY No 4106 Y LEYES PROVINCIALES DEL NORDESTE
}

Samuel Nelson Saiach

\section{A modo preliminar}

La administración tiene la posibilidad de ejecutar por sí en forma directa e inmediata sus propios actos (ejecutoriedad o auto tutela), en cambio el particular siempre debe ocurrir a la jurisdicción para hacer valer sus derechos.

Esta prerrogativa de auto tutela de la administración tiene límites que surgen de la ley y de garantías constitucionales que permiten el equilibrio entre poder y libertad.

Así, cuando el acto administrativo adquirió estabilidad o cosa juzgada administrativa y generó derechos subjetivos en favor del administrado, el acto se torna irrevocable y la administración no puede ejercer la auto tutela de ejecutar sus propios actos revocándolo en forma directa a través de otro acto administrativo.

Justamente esta imposibilidad revocatoria del acto administrativo que ha comenzado generar derechos subjetivos que se encuentra cumpliendo a favor de los administrados determinan el marco de seguridad jurídica de los derechos adquiridos de propiedad (art. 14 y 17 C.N.) y la administración está obligado a acudir a la justicia si considera que es lesivo al derecho objetivo para que esta disponga su nulidad.

Como lo afirma el maestro Revidatti en busca del equilibrio de las relaciones poder y libertad, debe dotarse a la administración de la posibilidad de que se legitime solicitando la nulidad de su propio acto.

Recordemos que los actos administrativos defectuosos cualquiera sea su gravedad -excepto los actos jurídicamente inexistentes-gozan de los caracteres de obligatoriedad, presunción de legalidad y ejecutoriedad (arts. 181/182 de la Ley $\mathrm{N}^{\circ} 3460$ ).

\footnotetext{
${ }^{1}$ Profesor Titular por concurso de Derecho Administrativo II y Profesor Adjunto por Concurso en Derecho Administrativo I de la Facultad de Derecho y Ciencias Sociales de la Universidad Nacional del Nordeste.
} 
Muchas de las veces por desconocimiento o voluntariamente los funcionarios deciden revocar en sede administrativa actos administrativos que ya han sido notificados y se encuentran en vía de cumplimiento, lo que trae como consecuencia su nulidad por incompetencia y en su caso indemnizaciones económicas por los daños y perjuicios que ocasionan al administrado afectado.

La acción de lesividad, justamente, es un proceso al alcance de la administración para que pueda anular un acto que considera lesivo al derecho objetivo y restablecer la legalidad.

Así dice Revidatti:

En las antiguas leyes de contencioso se preveía una o dos acciones que protegían un tipo de derecho: el subjetivo; las acciones legisladas eran la subjetiva o de plena jurisdicción y la lesividad. La primera era iniciada por el particular..; la segunda por el Estado contra el particular..., en aquellas oportunidades en que el acto aparecía viciado, pero sin que él pudiera ser enmendado en sede originaría; es decir que no podía rectificar o extinguir el acto en sede administrativa por haber alcanzado estabilidad. ${ }^{2}$

Existen doctrinas en contra del instituto - García de Entrerría- que consideran que consiste en un falseamiento del sistema procesal administrativo y una interpretación equivocada de los actos propios. ${ }^{3}$

\section{Concepto}

Podemos decir que la acción de lesividad, es la obligación legal que tiene la administración de solicitar judicialmente la nulidad de sus propios actos por razones de ilegitimidad cuando no puede ejercer revocatoria directa, previa declaración de lesividad del derecho objetivo.

Como afirma, Revidatti, "es el de la acción de lesividad, es decir la anulación total o parcial de los actos administrativos irrevocables, siempre que ellos previamente sean declarados lesivos por razones de ilegitimidad" .

\footnotetext{
${ }^{2}$ Lo contencioso administrativo de la Pcia de Ctes. Ley $\mathrm{N}^{\circ} 4106$, comentada, Cicero ediciones Corrientes, p. 67, año 1997.

${ }^{3}$ Acción de Lesividad - Revista de Administración Pública, $N^{\circ}$ 88, p. 210

${ }^{4}$ Lo Contencioso Administrativo en la Provincia de Corrientes, Comentada, Ley 4106, p. 71.
} 
En este sentido, nos estamos refiriendo a actos que otorgan derechos y beneficios a los administrados, no cargas u obligaciones o gravámenes, en cuyos casos si los puede revocar directamente pues en ese caso favorecen su situación jurídica.

Ahora bien, si concebimos que — así está consagrado objetivamente en el derecho vigente y lo entiende la jurisprudencia- el acto administrativo una vez notificado adquiere estabilidad, pero si está afectado de vicios graves o leves la administración no puede retirarlo, modificarlos o sustituirlos por sí mismo, debe obligatoriamente acudir a la jurisdicción para su anulación, para ello entonces debe iniciar la acción de lesividad, salvo claro está las excepciones previstas por el ordenamiento jurídico.

No coincidimos con algunos autores que afirman que en el caso de empleo público y especialmente en la legislación correntina esté prevista la nulidad en sede administrativa cuando las designaciones de agentes públicos fueron dictadas violando los requisitos para su ingreso, pues la ley especial deroga a la general:

Entre los derechos de los funcionarios de facto, apunta Diez que sólo podrían aspirar al cobro de los sueldos por el período de desempeño, pero nunca invocando como título el nombramiento irregular, sino por aplicación de la doctrina del enriquecimiento sin causa, lo que obviamente no les asigna derecho a la reincorporación luego del cese dispuesto por revocación de su designación.

Con lo expuesto, quiero evidenciar que no está en juego la garantía de estabilidad en el empleo, pues esta sólo es predicable de quienes ingresaron conforme a derecho en condiciones de igualdad con otros potenciales aspirantes (art. 16 C.N.). Analizando la Ley que rige el empleo público en la Provincia de Corrientes, la Ley $\mathrm{N}^{\circ} 4067$, en su Capítulo VI, prescribe los recaudos de "Admisibilidad de ingreso" y establece que "Previa a la designación, el interesado deberá presentar en tiempo y forma que determine esta ley y su reglamentación, los documentos y certificaciones que corresponda, sin las que no se podrá dictar instrumento de designación" (art. 19), remarcando que "El personal que ingrese como permanente lo hará en los niveles escalafonarios establecidos en la presente ley, cuyo ingreso se realizará conforme a lo dispuesto en esta ley y su reglamentación" (art. 21), agregando rotundamente que "No se podrá designar nombrar o contratar a agentes sin que previamente existan vacantes y/o partidas presupuestarias disponibles" (art. 22). 
Las consecuencias de la inobservancia de los recaudos para el ingreso se encuentran previstas en el art. 20 del Estatuto, que prescribe categóricamente que: "Las designaciones efectuadas en violación a lo dispuesto en los arts. 18, 19 y 24 de esta ley o cualquier otra norma vigente podrán ser declaradas nulas, en cualquier momento". La Reglamentación agrega en su artículo homónimo que: "Corresponde a la autoridad que dispuso la designación, sin perjuicio del derecho de avocación por la autoridad superior, declarar su nulidad cuando fuese efectuada en violación a lo dispuesto por los arts. 18, 19 y 24 de la ley o de cualquier otra norma vigente". 5

Si bien es abundante la doctrina y la jurisprudencia que sostienen el criterio en observación, hay que aclarar que ello surge de un análisis de la legislación nacional y no de Corrientes, que su régimen es distinto como veremos.

Lo primero que debemos advertir que la nulidad es una sanción y se tiene en cuenta la gravedad del vicio no la causa del vicio, ergo se aplica la norma que regula la extinción de los actos por nulidad prevista en la Ley $\mathrm{N}^{\circ} 3460$.

La norma del art. 20 dice que las designaciones efectuadas en violación a la ley de empleo público "podrán declararse nulas en cualquier momento".

Pero no lo regula, sino que establece la sanción que sufren dichos actos con vicios graves de origen.

Establece la posibilidad que la autoridad competente pueda declarar (lesividad pública) dentro del plazo de prescripción de los vicios previstos por la normas de la Ley $\mathrm{N}^{\circ} 3460$ (no en cualquier momento) que le da contenido a la causal de nulidad prevista en el art. 175 inc. e), pero que se deberá solicitar su anulación a través de la acción de lesividad prevista en el art. 184 y art. 55 inc. "e" de la Ley $\mathrm{N}^{\circ} 4106$, salvo las excepciones prevista en el art. 183.

La Ley $\mathrm{N}^{\circ} 4067$ no regula sobre los elementos y vicios de los actos administrativo, sino sobre la relación contractual de empleo público, es decir que respecto a la materia de nulidades no deroga la general.

Dice el Prof. Rey Vázquez:

Ello significa que, por aplicación del principio lex specialis derogat generalis, es que la norma del art. 20 de la Ley $\mathrm{N}^{\circ} 4067$ desplaza, por pp. 93/94.

${ }^{5}$ Luis Eduardo Rey Vázquez, Revista Digital de Derecho Administrativo Venezolano $N^{\circ} 6 / 15$, 
su especialidad, a las normas que de manera general regulan lo relativo a la revocación de actos administrativos (Arts. 175 a 184 de la Ley $\mathrm{N}^{\circ}$ 3460 de Procedimientos Administrativos). ${ }^{6}$

En su caso el legislador debió establecerlo expresamente, pues la ambigüedad de la redacción (podrá declarar la nulidad en cualquier momento) del art. 20 dejaría librado a la voluntad del funcionario anular la designación de un agente argumentando vicios graves, que inclusive pudo haber sido designado por un acto dictado por él mismo, quien no podría ir contra su propio acto y violar así el principio de buena fe.

La reglamentación sólo establece la competencia de quien debe ser el funcionario con competencia para declararlo, no otra, lo que es regla de toda atribución de competencia, pues ésta es restrictiva a quien fue adjudicada y/o al Superior Jerárquico cuando corresponda.

En la norma del art. 20, sin ninguna duda, que se aplica la excepción que prevé el art. 183 de la Ley $\mathrm{N}^{\circ} 3460$, cuando el agente tiene conocimiento del vicio que sería la causal prevista la que no es absoluta, por cuanto se debe diferenciar si el agente colaboró en la producción del vicio, como el ejemplo que menciona el artículo comentado (p. 89) "la revocación por carecer de uno de los requisitos para el ejercicio del cargo (en el caso, título profesional habilitante)"o no colaboró. Aquí juega la excepción prevista, pero no en el supuesto de la falta de concurso como lo explicaremos, donde la decisión de llamar a concurso no depende del agente sino de la administración.

Consideramos que la Ley $\mathrm{N}^{\circ} 4067$ no deroga la Ley $\mathrm{N}^{\circ} 3460$ sino que se aplica las excepciones allí prevista y que el mismo autor lo comenta y abona con jurisprudencia de la Corte (p. 98-fallo "Almagro").

Como cualquier supuesto que sea necesaria la nulidad cuando se han generados derechos subjetivos, se habilita la declaración en sede administrativa, como lo exige el mismo referido art. 20, siempre cuando concurre alguna de las excepciones establecidas por el art. 183 de la Ley $\mathrm{N}^{\circ} 3460$.

La normativa que regula sobre los vicios y nulidades de los actos administrativos prevé que los actos afectados de vicios graves (nulos de nulidad absoluta) gozan de presunción de legitimidad y ejecutoriedad lo que se produce cuando pp. 93-94.

${ }^{6}$ Luis Eduardo Rey Vázquez, Revista Digital de Derecho Administrativo Venezolano ${ }^{\circ}$ 6/15, 
el acto fue notificado, es decir que al generar derechos subjetivos el órgano que declare la nulidad deberá romper esa presunción, en sede judicial, salvo las excepciones previstas ${ }^{7}$

Tampoco es aplicable la norma cuanto establece que lo podrá declarar "en cualquier momento", pues nuestro régimen de nulidades regula que los vicios graves prescriben a los 10 años y los leves a los 3 años.

Por otra parte la Ley $\mathrm{N}^{\circ} 4067$ regula excepciones a las normas de ingreso por concurso que es a lo que apunta el autor del referido ensayo doctrinario (p. 94).

En su art. 266 la Ley $\mathrm{N}^{\circ} 4067$ dice textualmente:

Artículo 266: Por Reglamentación se establecerá el procedimiento del llamado a Concurso para la cobertura de vacantes que se opere en virtud a lo establecido en el presente Escalafón.

Por causas excepcionales que serán previstas en la Reglamentación, podrá obviarse el Concurso y se procederá a la designación o promoción directa. ${ }^{8}$

El Poder Ejecutivo nunca reglamentó el régimen de concursos, por la cual más del $80 \%$ de los empleados del sector estatal ingresaron a planta permanente sin concurso y sí reglamentó la segunda parte del art. 266 que refiere a las excepciones al concurso. Entonces al no reglamentar los "concursos" el mismo Pode Ejecutivo crea la imposibilidad de ingresar por merito y luego no podría pretender usar su negligencia regulatoria para cuando se le ocurra anular en sede administrativa actos de designación que inclusive el mismo los pudo haber dictado, entonces al no encuadrarse dentro de la excepción del art. 183 de la Ley $\mathrm{N}^{\circ} 3460$ (conocimiento del vicio) debe recurrirse a la acción de lesividad y aun así se deberá rechazar la pretensión anulatoria por cuanto es de exclusiva culpa del Poder Ejecutivo no reglamentar y no llamar a concurso.

Gordillo, sostiene esta posición y acepta la excepción cuando existe connivencia dolosa entre funcionario y el particular ${ }^{9}$ o como dice la Procuración del Tesoro cuando hay "mala fe del particular"10 o como lo afirma Revidatti "cuando el particular provoca el vicio". ${ }^{11}$

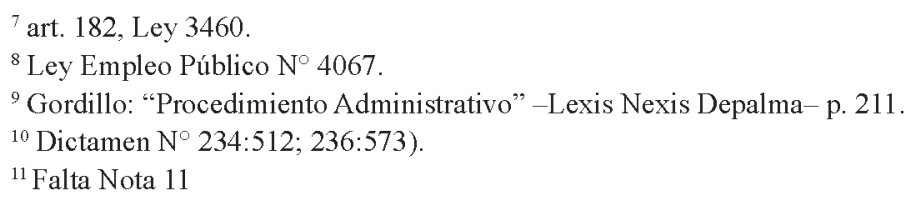


Sin perjuicio de que la legislación nacional, la doctrina y la jurisprudencia consideren la posibilidad de que los actos irregulares pueden ser anulados en sede administrativo se ve limitado en nuestro régimen jurídico correntino por los efectos que le otorga la ley ${ }^{12}$ a los actos nulos es decir de que se presumen legítimos y son ejecutorios.

Hay que advertir que la Ley $\mathrm{N}^{\circ} 4067$, art. 19, dice: "Admisibilidad de ingreso", "Previa a la designación, el interesado deberá presentar en tiempo y forma que determine esta ley y su reglamentación, los documentos y certificaciones que corresponda, sin las que no se podrá dictar instrumento de designación".

O sea quien tiene la obligación de no designar al personal sino se cumplen los requisitos de ingresos que prevé la ley es el funcionario que tiene dicha competencia y no puede hacer cargar la culpa al funcionario designado salvo que hubiera colaborado en la producción del vicio.

En este sentido ya tiene jurisprudencia sentada el S.T.J.C.:

Sí, el vicio consistía como lo afirma el Estado en el juicio al contestar la demanda por sí y por el ente descentralizado que el acto de designación en el cargo de planta permanente de... no es válido porque carecía de la homologación del Poder Ejecutivo esta es una argumentación que no puede ser por dos razones, la primera porque la falta de cumplimiento procedimental no es imputable al agente, quien entiendo, de ninguna manera puede cargar con los incumplimientos que le compete al área de diligencia de la administración y por otro lado como lo he dicho anteriormente si se aplica la sanción del art. 11 de la Ley $\mathrm{N}^{\circ} 3478$; esta es de nulidad, el tramite que debió impetrase, es ante la jurisdicción... ${ }^{13}$

Advertirá que también ha dicho la jurisprudencia:

Estabilidad empleado público-Garantía constitucional. Existiendo en Entre Ríos una garantía constitucional que ampara la estabilidad en el empleo público con un alcance no previsto en el orden nacional (artículo 21 Constitución de Entre Ríos) y existiendo también un Código Procesal que ha previsto la acción de lesividad, provincial o municipal, no puede revocar por sí o ante sí actos administrativos que

\footnotetext{
${ }^{12}$ Art. 182, Ley N ${ }^{\circ} 3460$.

13 "Qustidiano Andrés Vicente c / I.O.S.C.O.R. y Estado de la Provincia de Corrientes s / Acción Contenciosa Administrativa"-Expte N ${ }^{\circ} 13402 / 97$.
} 
generan derechos subjetivos, ni aún en el supuesto de considerarlos nulos y de nulidad absoluta, supuesto que no puede razonablemente sostenerse que exista en el caso planteado. ${ }^{14}$

En el derecho comparado la Sala Contencioso Administrativa de la Corte Suprema de Justicia de Ecuador ha recogido y desarrollado el criterio al que nos referimos:

si por alguna circunstancia no se da cumplimiento a la disposición legal de la forma de designación del personal legislativo permanente, esto es que no se haya designado previo concurso de merecimientos y oposición, el efecto no es que de permanente el servidor se convierta en ocasional; sino que el nombramiento adolezca de ilegalidad, circunstancia ésta que de ninguna manera faculta a la autoridad nominadora para prescindir de los servicios del irregularmente designado, ya que conforme al art. 2, el personal legislativo permanente goza de estabilidad. En tal evento lo legalmente pertinente es demandar la ilegalidad del acto administrativo de nombramiento, que no puede ser dejado sin efecto por sí mismo, por crear derechos subjetivos y en acatamiento de la disposición constitucional contenida en el art. 119 de la Carta Política, demandar ante el Tribunal de lo Contencioso Administrativo en acatamiento de lo que dispone el lit. d) del art. 23 de la ley de esa jurisdicción mediante el recurso que la doctrina denomina de lesividad. ${ }^{15}$

\section{Fundamento y Finalidad}

No estamos totalmente de acuerdo con la doctrina más caracterizada por su calidad doctrinaria que sostiene que la necesidad de este tipo de proceso, reside en el principio de que "nadie puede ir en contra de su propio acto". ${ }^{16}$

\footnotetext{
${ }^{14}$ Fernández Alfredo Alejandro c/ Municipalidad de Concepción del Uruguay s/ Contencioso administrativo. S SCPA04 PA 0000000405 14-03-91 MANESA".

${ }^{15}$ Juan Pablo Aguilar Andrade-Apuntes sobre la Acción de Lesividad-Revista de Derecho Administrativo-11 de noviembre de 2009. Sentencia de 15 de noviembre de 2000, Ignacio Zambrano vs. Congreso Nacional, G.J., XVII, 5, 1484.

${ }^{16}$ González Pérez: La declaración de lesividad, Revista RAPN ${ }^{\circ} 2^{\circ}$, pp. 60-62; Tomás Hutchinson, Derecho Procesal Administrativo, Tomo III, p. 627.
} 
Pues ello ocurre en los casos de excepción que prevé la normativa del art. 183 de la Ley $\mathrm{N}^{\circ} 3460$, aplicable también en los supuestos del art. 184 y ahí la administración va contra su propio acto y lo puede hacer en sede administrativa.

Al contrario consideramos que el fundamento se encuentra en la estabilidad del acto como carácter esencial y el principio de seguridad jurídica como garantía constitucional a los derechos ya adquiridos por los administrados por un acto administrativo nulo o anulable y ahí reside la obligación de la administración de solicitar judicialmente su retiro del mundo jurídico.

Ha dicho la Corte: Se trata de un principio de vital significancia, que tiene su base constitucional en la garantía de la propiedad (arts. 14 y 17 de la Constitución Nacional) y a cuyo través se consolida uno de los pilares del ordenamiento jurídico, cual es el de la seguridad. ${ }^{17}$

Y este principio de seguridad jurídica prevalece sobre el principio de legalidad como lo afirma Rey Vázquez en el artículo doctrinario mencionado (p. 83) y la jurisprudencia que analiza. ${ }^{18}$

Justamente en el caso "Carman de Cantón, Elena" la Corte utilizó este criterio de que la negligencia correspondió a la administración y no a la actora, aún cuando hubiera conocido el vicio.

La estabilidad es la regla, la revocación la excepción.

Lo cierto sean actos nulos o anulables, si el acto adquirió estabilidad (generó derechos subjetivos) la administración no lo puede modificar, sustituir o revocar, y debe acudir a la jurisdicción salvo las excepciones previstas, que lo son para ambos tipo de actos viciados.

Decíamos que cuando el acto comenzó a generar derechos subjetivos, existe la imposibilidad de que el mismo órgano que lo dictó lo revoque, pues tiene una prohibición expresa del art. 101 inc. e) de la Ley $\mathrm{N}^{\circ} 3460$ (principio de seguridad jurídica) de dictar actos que vulneren el principio de irrevocabilidad de los actos administrativos, en este caso estaría viciado el "contenido del acto".

Indudablemente que existen muchas veces un acto generador de derechos que se encuentre afectado en su validez por razones de ilegitimidad -vicios graves o leves- y no puede entonces encorsetarse a la administración en la imposibilidad de que cuando estos actos violen el derecho objetivo no pueda retirarlos del

${ }^{17}$ Fallos 310: 1045.

${ }^{18}$ CSJN, 14/08/1936, "Carman de Cantón, Elena c. Estado Nacional", Fallos 175:368. 1. 
mundo jurídico.

Entonces, la finalidad será permitirle a la administración retirar del mundo jurídico los actos administrativos afectados de algún vicio que afecte el derecho objetivo que favorece el interés privado, proveyéndolo de un mecanismo procesal adecuado y que garantice el derecho de defensa de los sujetos beneficiados por dicho acto.

Esta finalidad, no es la del funcionario u órgano que dictó el acto, sino el interés público lesionado por un acto ilegitimo, pues no puede mantenerse un acto viciado en el mundo jurídico, existe una relación directa entre interés público $\mathrm{y}$ actos viciados, pero que por razones de seguridad jurídica se debe solicitar judicialmente su retiro del mundo jurídico.

A dicho la jurisprudencia Mendocina:

Acto administrativo-Irrevocabilidad. Si queda al arbitrio de la Administración revocar por sí y ante sí los actos administrativos que han causado efectos, sólo por reputarlos nulos de nulidad absoluta y manifiesta, no existe la estabilidad del acto administrativo ni la presunción de legalidad que constituye otra de sus características y no tendría razón de ser la acción de lesividad prevista en el Código Procesal Administrativo de la Provincia (Decreto Ley 7061 ratificado por Ley $\mathrm{N}^{\circ} 7504$ ), justamente establecida para impugnar judicialmente los actos administrativos amparados por la irrevocabilidad o cosa juzgada administrativa. El acto administrativo que genera derechos subjetivos en favor de un administrativo es irrevocable para la propia administración, ya que goza de estabilidad (cosa juzgada administrativa), pudiendo sólo la Administración, para invalidar dicho acto, recurrir a la autoridad judicial competente. ${ }^{19}$

\section{Características}

\section{a) Ilegitimidad}

Dijimos que el acto administrativo que se pretende retirar debe ser ilegítimo en razón de estar afectado de vicios leves o de vicios graves que provocan una

\footnotetext{
${ }^{19}$ Benítez Eduardo Alcides c/ Municipalidad de Concepción del Uruguay s/ Nulidad del decreto n.9803/87 del Departamento Ejecutivo Municipal. s SCPA04 PA 0000000883 15-06-92 SD SOLARI".
} 
lesión al derecho objetivo (falta o vicio en algunos de sus elementos esenciales).

Los acto jurídicamente inexistente que comenzaron a generar derechos subjetivos, también deben ser objeto de este proceso, no basta la simple declaración, esta valdrá para iniciar la acción de lesividad pues la administración no lo puede invocar en su favor. Es decir los únicos que no son objeto de este proceso son los actos perfectos, de ahí la necesidad de la declaración de lesividad.

\section{b) Irrevocabilidad}

En segundo lugar la Irrevocabilidad del acto administrativo, reconocida su estabilidad como carácter propio y que la administración no puede en determinadas circunstancias retirarlos -excepción al principio de ejecutoriedad- (arts. 184 y 183) sin acudir a la jurisdicción y como principio especial de consolidación del principio de la irrevocabilidad de los actos declarativos de derechos consagrado por el art. 101 inc. e) de la Ley $\mathrm{N}^{\circ} 3460$.

Los actos nulos (afectados de vicios graves) o anulables (afectados de vicios leves) cuando se encuentren generando derechos subjetivos que se estén cumpliendo, en ambos casos salvo las excepciones establecidas por la ley, deben ser retirados en sede judicial.

La formula sería entonces:

Los actos nulos los debe retirar la administración, salvo que se encuentren generando prestaciones pendientes de ejecución, en cuyo caso debe ocurrir a la jurisdicción, salvo que no haya sido notificado, que el sujeto interesado haya conocido el vicio; que lo beneficie y no perjudique a terceros o que haya sido otorgado expresa y válidamente a titulo precario. ${ }^{20}$

Los actos anulables del que hayan nacido derechos subjetivos los debe retirar la jurisdicción salvo que no haya sido notificado, que el sujeto interesado haya conocido el vicio; que beneficie al administrado sin causar perjuicio a terceros o que haya sido otorgado expresa y válidamente a titulo precario. ${ }^{21}$

El S.T.J.C. ha dicho:

V. Entrando en el fondo de la cuestión, la actora ha iniciado la demanda reclamando como objeto, la nulidad del decreto de baja el reintegro del cargo u funciones que ocupaba, así como el reclamo de daños y perjuicios.

(...) Esa derogación se hizo sin cumplir con el requisito de la causa

${ }^{20}$ Art. 184, Ley 3460 .

${ }^{21}$ Art. 183, Ley 3460. 
de hecho y de derecho, no se cumplió procedimiento pues sin tramitar la "acción de lesividad" prevista en la Ley $\mathrm{N}^{\circ} 4106$ (art. 55 inc. e) y ordenada por el art. 184 de la Ley $\mathrm{N}^{\circ} 3460$, este último precepto OBLIGA a la administración pública a pedir "judicialmente su anulación" cuando "hubiere generado prestación pendiente de cumplimiento" y la relación de empleo configura, de acuerdo a la ley..., prestaciones pendientes derivadas de la inamovilidad de la función; derogar sin más el decreto $\mathrm{N}^{0} 4660$, sin pasar por la acción de lesividad, que es la vía idónea para ello (Diez, M.M. "Derecho Procesal Administrativo -p. 266) configura nulidad del acto".

En consecuencia corresponde declarar que el acto administrativo atacado Decreto $\mathrm{N}^{\circ} 330$ de fecha 26 de julio de 1999 del cual derivó la lesión. ${ }^{22}$

El Superior Tribunal también sostuvo:

si el acto tuviera vicios que lo pudieran tornar nulo o anulable... también goza de presunción de legitimidad... y no puede ser revocado, modificado o sustituido en sede administrativa. Salvo en los casos enunciados en el art. 183, a los que deberá referirse el acto derogatorio, solicitando su anulación al poder judicial. (...) De allí que el fallo impugnado no necesitó justificar los extremos del art. 183, sino la recurrente quien debió hacerlo, bastando para la validez que el Superior Tribunal reivindique la obligación de anular en sede judicial por la acción de lesividad para hacer inútil toda consideración sobre nulidades argumentadas de la norma anterior. ${ }^{23}$

\section{c) Sujeto Activo}

Sin perjuicio de quien dicta el acto lesivo y declara de lesividad pública, el sujeto activo será siempre el Poder Ejecutivo o un Ente descentralizado o órgano extra-poder, excepción al principio de que la legitimación activa la ostenta quien se encuentra afectado en un derecho subjetivo o de un interés directo y personal.

Va de suyo que solamente puede estar legitimado el Poder Ejecutivo cuando el acto lesivo proviene de la organización centralizada o de alguno de los otros dos poderes en función administrativa; la autoridad superior cuando el acto lesivo

${ }^{22}$ EXPTE No 18985 , Sentencia de fecha 10/11/05.

${ }^{23}$ En los autos, EXPTE $N^{\circ} 17036 / 99$, Sentencia $N^{\circ} 61 / 05$, entre otros.. 
fue dictado por un órgano que integra la organización descentralizada o de los órganos extra-poder.

También lo puede plantear el Fiscal de Estado quien tiene autonomía y personería constitucional para solicitar por sí mismo la nulidad de un acto administrativo, reglamento o contrato que pudiera perjudicar los intereses fiscales. ${ }^{24}$

Indudablemente que al no poder permitirse la existencia en el mundo jurídico de un acto viciado e irrevocable en sede administrativa, debió dotarse a la administración de legitimación procesal activa para solicitar su anulación en sede judicial.

\section{d) Sujeto Pasivo}

El o los particulares beneficiados por el acto lesivo que integren la litis pues los efectos de la sentencia no son erga homes, sino entre partes.

\section{Requisitos administrativos}

\section{Regla}

a) Que el acto administrativo ejecutorio lesivo sea declarativo o constitutivo de derechos subjetivos. O sea que exista una conducta debida por el Estado que beneficie al administrado en violación del orden jurídico y en forma exclusiva.

La pregunta sería ¿si sólo procede contra actos ejecutorios o si también procede contra los Reglamentos y contratos?

En el caso de los reglamentos en principio no procede, porque la administración tiene la facultad de derogarlos en cualquier momento en tanto y siempre que no afecte derechos adquiridos que se encuentren cumpliendo, en cuyo caso deberá demandar, ${ }^{25}$ vía la acción de lesividad.

En el caso de los contratos consideramos aplicable a los actos separables según lo establecido en el art. 237 de la Ley $\mathrm{N}^{\circ} 3460$ y art. $3^{\circ}$ inc. b) de la Ley $\mathrm{N}^{\circ} 4106$.

La subsistencia del contrato dependerá de la importancia que tiene el acto separable cuyo retiro se solicita. Si afecta a su integridad caerá el contrato, sin perjuicio de las responsabilidades que correspondan a cualquiera de las partes

${ }^{24}$ Art. 175 de la Constitución Provincia, Segunda Parte.

${ }^{25}$ Art. 226 de la Ley $\mathrm{N}^{\circ} 3460$. 
como consecuencia de ello. ${ }^{26}$

La jurisprudencia federal ha dicho:

Contratos - colaboración de terceros en la ejecución de servicios postales- Estado usuario - alteración de la base económica-financiera en la prorroga - naturaleza administrativa de los actos que aprobaron y anularon la convención - nulidad: requisitos - fundamentos obiter dicta - jurisprudencia CSJN - FICHA $\mathrm{N}^{\circ} 3568$. El acto por el cual se aprobó el contrato y el acto por el cual se declaro su "anulabilidad" son actos administrativos, cuya validez excede la consideración de esta litis. Sin embargo, a mayor abundamiento, cabe recordar que la Corte Suprema de Justicia de la Nación ha sostenido que, si como consecuencia del acto (en el caso el que aprobó el contrato o las prorrogas del mismo) se generaron prestaciones cumplidas (reparto de las misivas de la demandada) y otras en vías de cumplirse (el pago pertinente), sólo podría impedirse su subsistencia y la de los efectos pendientes, mediante la declaración judicial de nulidad (fallos: $300: 253 ; 305: 2170$; o ed., 108-586, F. 37.797); A punto tal que la revocación dispuesta en sede administrativa -sin ejercer la acción de lesividad-configura, a su vez, un acto viciado de "ilegalidad manifiesta" (Barra, la nulidad del acto administrativo y los efectos de su declaración). ${ }^{27}$

La jurisprudencia de la Provincia de Mendoza también tiene dicho al respecto:

Contrato administrativo - bis- $\mathrm{c}$ - rescisión unilateral por el Estado - procedimiento - daños. Cuando de un contrato administrativo ilegítimo han nacido derechos para el cocontratante particular, no puede por sí misma la administración pública extinguirlo en sede administrativa, sino que debe acudir al Poder Judicial, mediante acción de lesividad. La facultad rescisoria por razones de oportunidad, mérito o conveniencia, está incita en todo contrato celebrado por el Estado y ejercida por la administración por motivos de interés público. No obstante, el interés privado debe ser respetado y de allí que debe

\footnotetext{
${ }^{26}$ (Manuel Diez con Colaboración de Tomás Hutchinson-Derecho Procesal Administrativo, Ed. Plus Ultra, p. 302).

${ }^{27}$ C. Civ. Com. Fed: 1, 06/05/94 SA. Organización Coordinadora Argentina C/Secretaria de Inteligencia de Est. de la Pres de la Nac. S/Cobro de Pesos. Causa $N^{\circ}$ 5824/92).
} 
evitarse el quebranto del particular mediante justa indemnización. ${ }^{28}$

b) Que existan razones de ilegitimidad es decir que el acto se encuentre afectado de un vicio grave o leve.

No pueden retirarse actos administrativos perfectos porque se estaría autorizando que por voluntariedad y/o capricho de algún funcionario pueda en cualquier momento solicitar judicialmente el retiro de cualquier acto, so pretexto de la lesión al interés público, encuadrando esta conducta en la figura de la arbitrariedad.

La doctrina no tiene dudas respecto a los actos afectados de vicios leves, en razón de que los mismos necesitan una mayor y más profunda investigación y prueba de la gravedad del vicio, o sea cuando están afectados de vicios no tan groseros o manifiestamente ilegítimos (art. 183-Ley No 3460 de Procedimientos Administrativos de Corrientes), salvo las excepciones legalmente previstas.

Con respecto a los actos afectados de vicios graves o sea aquellos que tienen sanción de nulidad, el principio general es que el órgano que debe revocarlo o sustituirlo es la administración, salvo cuando hubieren generado prestación pendientes de ejecución (art. 184-Ley No 3460 de Procedimientos Administrativos de Corrientes), con las excepciones legalmente previstas.

\section{Excepciones a la irrevocabilidad en sede administrativa}

a) Cuando el acto no se hubiese notificado (art. 127) porque no tiene ejecutoriedad (art. 137 y art. 138);

b) Cuando el administrado hubiera conocido el vicio, porque lo beneficia ilegítimamente, se refiere cuando administrado colabora en la formación del acto viciado (v. gr. cuando acepta la designación en un cargo no teniendo la edad exigida), no se configura cuando el dictado del acto viciado no depende de su voluntad sino de la propia administración (v. gr. designación sin concurso o falta de aprobación de la designación);

c) Cuando la modificación o el retiro del acto favorece al interesado sin perjudicar a terceros porque lo beneficia legítimamente, lógicamente como dice Revidatti, sino hay agravio, no hay necesidad de recurrir a la Justicia; ${ }^{29}$

d) Cuando el derecho se hubiere otorgado expresa y válidamente a titulo

${ }^{28}$ Expte.: 49003 Carátula: Mercado, Raúl Contra Municipalidad De Guaymallen. Acción Procesal Administrativa. Libro: S246 fojas: 471 fecha: 21-06-94 Preopinante: Aguilar Adherentes: Salvini, Llorente. Disidentes".

${ }^{29}$ FALTA NOTA 29. 
precario, porque el acto carece de estabilidad, en este supuesto como lo establece la norma, al dictarse el acto la precariedad debe ser expresada en el contenido del acto, la misma no se presume y la revocación no puede ser intempestiva ni arbitraria;

e) Cuando se produce la revocabilidad por demérito o ilegitimidad sobreviniente (art. 158), en este caso se debe indemnizar y por ello entonces no hay necesidad de ocurrir a la justicia;

f) Cuando se revoca el acto por distinta valoración técnica o política (art. $161^{\circ}$, porque se indemniza;

g) Por demérito o ilegitimidad derivada de la acción del particular (art. 163, porque el administrado se beneficia ilegítimamente;

h) Por razones de carácter general, porque el interés público está por sobre el interés individual (art. 164).

Las causales previstas en los incs. a) al d) se justifican porque no afectan derechos subjetivos.

Las previstas en el inc. e) y f) procede porque se indemnizan.

$\mathrm{Y}$ los previstos en el inc. g) y h) proceden porque no crean responsabilidad para la administración.

\section{Presupuesto Procesal}

a) Que sea declarado previamente lesivo al interés público y dicha declaración autorice la iniciación de la acción de lesividad.

Es decir que debe dictarse un nuevo acto administrativo sin substanciación debidamente fundado declarando la lesión que produce al interés público, previo dictamen del Servicio Jurídico Permanente del órgano.

El concepto de "interés público" es un concepto jurídicamente indeterminado que no representa una facultad discrecional de la administración.

No debe confundirse la discrecionalidad con el concepto jurídico indeterminado, en los primeros la norma le otorga a la administración la opción de escoger una solución entre varias soluciones igualmente justas. En los segundos, la norma no determina en forma exacta cuales son los límites del concepto jurídicamente indeterminado, en tales casos no hay más que dos posibilidades o se configura o no el concepto dado por la norma, es decir sólo se admite una solución justa. La administración debe determinar con exactitud cuándo configura la lesividad 
pública al dictar el acto que así lo declara, no sólo invocarlo, debe fundamentar la ilegitimidad declarada.

La doctrina se ha expresado: "la obligatoriedad de la interposición de la demanda se correlaciona, pues, con el deber de emitir el acto anulatorio "no ejecutorio" o "declarativo de la lesividad", pues éste viene a constituir el presupuesto lógico de la demanda". 30

La Corte ha dicho:

IV...Estimo que ello es también derivación necesaria e indubitable de lo establecido por la misma ley de procedimientos administrativos en sus arts. 10, 70 y cc., Y que asimismo halla su fundamento en elementales razones que hacen al derecho de defensa del particular involucrado, quien ha de participar en dicho procedimiento a fin de poder ser oído y ofrecer las razones que hagan a su derecho (art. 10, inc. $f$, de dicha ley). Además, y a todo evento, sostener lo contrario importaría tanto como dejar librada la posibilidad de permitir a un abogado del Estado que, sin orden expresa, inicie por su solo ímpetu una pretensión de nulidad de un acto emanado de alguno de los órganos por él representados, lo que sin duda alguna resulta inadmisible, y contrario a lo normado por los arts. $10 \mathrm{y} \mathrm{cc}$. del decreto $411 / 80 \mathrm{y}$ sus modificaciones. ${ }^{31}$

En este sentido ha dicho el S.T.J.C.:

El cese o egreso del agente está previsto en el art. 70, para realizarse deberá dictarse otro acto administrativo que revoque el que constituyó el nombramiento del agente...

Esa revocación no puede hacerse simplemente por otro decreto, cuando ello afecta derechos adquiridos otorgados por la norma que se pretende derogar,... La acción cuando sea ejercida por la administración para obtener la revocación de su propio acto que ha adquirido estabilidad, requiere como instancia previa, expresamente establecido en la ley que haya un acto formal de declaración de lesividad"... Demás estar decir que la declaración deberá hacerla el Poder Judicial, pues

${ }^{30}$ Julio R. Comadira, Procedimientos Administrativos - Ley nacional de procedimientos administrativos, anotada y comentada, La Ley, Buenos Aires, 2002, tomo I, p. 344 y ss.

${ }^{31}$ AFIP (DGI) -se Solicita Revocación de Acto Administrativo-Acción de lesividad S.C. A.212, L.XLV (Recurso Extraordinario) Suprema Corte). 
respecto a las leyes y controles jurisdiccionales es de la esencia del Estado de Derecho. Ello en cuanto a los actos validos.

Si el acto tuviera vicios que lo pudiera tornar nulo (...) de acuerdo al art. 175 de la Ley N 3460 goza de presunción de legitimidad (art. 182 a.) y no puede ser revocado, ... en sede administrativa, si hubiera generado prestaciones pendientes de cumplimiento como en el caso., solicitando su anulación al Poder Judicial. ${ }^{32}$

b) Que el acto declarativo de lesividad se haya notificado

Consideramos que el acto declarativo se debe notificar fundado en el art. $114^{\circ}, 126,137$ y 138 de la Ley $\mathrm{N}^{\circ} 3460$.

En contra alguna jurisprudencia:

Acción de Lesividad-Notificación. La decisión de declarar lesivo un acto de la Administración tiene carácter declarativo, en consecuencia no se ve de qué manera afecta en forma concreta, directa e inmediata los derechos subjetivos de los administrados. La notificación sería conveniente pero no es esencial, puesto que contra la declaración de lesividad en sí misma no cabe recurso alguno. ${ }^{33}$

La notificación tiene que ver con la vigencia del acto, no con la recurribilidad o no del acto, por ello siempre se debe cumplir por cuanto en nuestro régimen jurídico es un elemento esencial del acto. ${ }^{34}$

Se le debe hacer conocer el acto, pues en nuestro sistema la notificación al ser un elemento esencial del acto e integra el elemento forma como declaración de la voluntad, dentro del Título VI de la Ley $\mathrm{N}^{\circ} 3460$, no será ejecutorio en su caso, ${ }^{35}$ no podrá ser la base procesal de la acción.

Pero además, el plazo de caducidad de la acción de lesividad se cuenta a partir de la notificación del acto declarativo de lesividad (art. 223-Ley Nº 3460).

\footnotetext{
¿Son recurribles los actos declarativos de lesividad pública?

$\$$ Superior Tribunal de Justicia en: "Z.H. E. c / Estado de la Pcia de Corrientes s/ Recurso Facultativo", Expte $\mathrm{N}^{\circ} 17.005 / 99$ ).

${ }^{33}$ Municipalidad de Concepción Del Uruguay S/ Acción De Lesividad. S Scpa04 Pa 0000001892 19-08-93 Ma Chiara Díaz".

${ }^{34}$ Título VI-Ley $\mathrm{N}^{\circ} 3460$.

${ }^{35}$ Art. 137 y 138 , Ley N 3460.
} 
Se considera que no son recurribles por cuanto son actos declarativos que no revocan el acto lesivo y por ello no afectan derechos subjetivos del beneficiario pues es un requisito pre procesal y quien anulará el acto lesivo será la justicia, es decir antes de la decisión judicial no existe agravio pues el acto lesivo sigue siendo ejecutorio.

Alguna doctrina considera intrascendente la notificación que al no afectar derechos subjetivos, justamente no existiría la posibilidad recursiva, porque no existiría causa, elemento esencial para la procedencia de los recursos administrativos, pues es un presupuesto procesal que no afecta al acto que se impugnará judicialmente.

\section{Puede suspenderse los efectos del acto lesivo en el mismo acto declara- tivo o por otro acto}

Afirmamos que no se puede suspender el acto lesivo en sede administrativa al encontrase irrevocable, consecuentemente cosa juzgada administrativa. Entonces quien no puede lo más, no puede lo menos.

El Prof. Revidatti, afirma: "La nulidad, es declarada por la administración, sin recurrir a la justicia. Esto hasta que el acto comienza a cumplirse, ya que si ha tenido principio de ejecución, deberá pedirse judicialmente la anulación". ${ }^{36}$

$\mathrm{Y}$ respecto a la suspensión como medida cautelar en sede administrativa y concordantemente, afirma: "Parece obvio, pero sin embargo es conveniente resaltarlo, que claro está, estas medidas precautoria habrán de regir solamente en el ámbito donde la Administración tiene esfera de competencia exclusiva, así, por ejemplo". ${ }^{37}$

Es lógico entonces que según art. 183 y 184 la administración una vez notificado el acto y generar derechos subjetivos pierdan la competencia exclusiva de revocarlo en sede administrativa, entonces también pierde la competencia para suspenderlo.

La doctrina mayoritaria (Hutchinson, Gordillo, Bustelo) rechazan también

${ }^{36}$ Procedimiento de Administrativo de la Provincia de Corrientes, Ley $N^{\circ} 3460$, Comentada, expresa, p. 196.

${ }^{37}$ Procedimiento de Administrativo de la Provincia de Corrientes, Ley N ${ }^{\circ} 3460$, Comentada, expresa, p. 196. 
la posibilidad de suspender el acto en sede administrativa, en contra Estrada, Comadira, pero quienes sostienen que debe iniciarse de inmediato la acción contenciosa y Canda sólo acepta pero durante el plazo general de 10 días dentro del cual la administración debe iniciar la acción de lesividad.

La mayoría de las leyes procesales y el nuestro (Ley $\left.N^{\circ} 4106-a r t .24\right)$, establece la posibilidad de que la administración solicite medida cautelar la que procederá con la simple solicitud al presentar en la demanda el acto que declara la lesividad, ergo, entonces no lo puede hacer en sede administrativa.

STJC tiene dicho.

Si la norma priva de la potestad revocatoria a la administración para no lesionar derechos subjetivos que se estén cumpliendo (art. 184 de la Ley $\mathrm{N}^{\circ} 3460$ ), con igual razón no podría suspender sine die el acto. Lo contrario llevaría a admitir la posibilidad de violar la garantía que la norma quiso proteger a través de una decisión administrativa "disfrazada" bajo la figura de la suspensión; lo que equivaldría a la revocación misma. ${ }^{38}$

El Procurador de la Corte siguiendo el criterio de Comadira considera que puede suspender en sede administrativa y a dicho:

A mi modo de ver, las facultades de que trata el arto 17 de la Ley $\mathrm{N}^{\circ} 19549$, sea que el acto irregular pueda ser revocado por razones de ilegitimidad en sede administrativa (primera parte) o bien que, por las mencionadas razones, su revocación deba instarse ante el Poder Judicial (segunda parte), han de desenvolverse, como indiqué, en el marco de una interpretación armónica del articulado de la Ley $\mathrm{N}^{\circ} 19549$, dentro del preceptivo carril de un procedimiento administrativo, al cabo del cual se dicte el acto que, en el primer caso, revoque el anterior o bien, para el segundo, declare la lesividad del acto, eventualmente-en ejercicio de lo normado en el art. 12 de la misma ley suspenda sus efectos, y finalmente dé la instrucción pertinente, por parte del órgano competente, para que se proceda al inicio de la acción judicial. ${ }^{39}$

\section{Prescripción de los vicios}

38 (STJ CAX 20/10 Sentencia 181 21/09/2011.

${ }^{39}$ (AFIP(DGI) - se Solicita Revocación de Acto Administrativo-Acción de lesividad S.C. A.212, L.XLV (Recurso Extraordinario) Suprema Corte). 


\section{Principio general}

Nuestra posición es clara, toda la materia de prescripción de derechos y obligaciones que nacen de leyes locales y de los vicios que afectan a los actos administrativos son de competencia provincial, ${ }^{40}$ posición adoptada por el nuevo Código Civil y Comercial. ${ }^{41}$

Cuando las leyes locales no lo regulan se aplica supletoriamente las previstas en el Código Civil.

En el orden federal no está legalmente establecido en la Ley $\mathrm{N}^{\circ} 19549 \mathrm{el}$ plazo de prescripción de los vicios, concordante con el art. 27-última parte-pero se debe sostener que los vicios graves y los leves prescriben según el plazo de prescripción de la materia objeto del acto lesivo previsto en el Código Civil y Comercial. Así los vicios graves prescribirán a los (5) años (art. 2560 C.C.C.) y los leves a los dos (2) años (art. 2562 C.C.C.).

Dentro de dicho plazo se deberá declarar la lesividad y accionar judicialmente dentro del plazo de 30 días. ${ }^{42}$

Las legislaciones extranjeras en general, al igual que la nuestra, establecen un plazo amplio para dictar el acto declarando la lesividad y uno breve de caducidad de la acción. Por ejemplo la legislación Española establece cuatro años para dictar el acto declarando la lesividad y dos meses para iniciar la acción judicial.

\section{Normas especiales}

La ley de Corrientes en su art. 181 y 182 establece la prescripción de los vicios leves en tres años y los graves en 10 años.

Así entonces la prescripción para dictar el acto de lesividad pública será de tres (3) o diez (10) años según el vicio sea leve o grave, comenzado contar desde la notificación del acto declarado lesivo.

Las legislaciones provinciales del Chaco y Misiones no prevén plazo de prescripción de los vicios, entonces se aplica el plazo previsto en el Código Civil y Comercial.

Formosa prevé sólo el plazo de caducidad a partir del dictado del acto lesivo.

\footnotetext{
${ }^{40}$ Art. 223 de la Ley $\mathrm{N}^{\circ} 3460$.

${ }^{41}$ C.C. y C. art. 2532 y 2560.

${ }^{42}$ Art. 25, Ley N ${ }^{\circ} 19549$.
} 


\section{Caducidad de la acción de lesividad}

En la Provincia de Corrientes según la normativa vigente caduca a los treinta (30) día hábiles judiciales, contados a partir de la notificación del acto declarativo de lesividad pública, que deberá ser dentro del plazo de prescripción de tres (3) o diez (10). ${ }^{43}$

Ahora bien ¿desde cuándo se cuenta el plazo de caducidad atento la superposición legislativa de la prescripción de derechos y el de caducidad de la acción judicial?

La prescripción se cuenta desde el momento en que fue notificado el acto anulable o nulo.

Es decir que la administración tendría tres años o diez años para dictar el acto declarando la lesividad pública a partir de la notificación del acto lesivo.

El plazo de caducidad judicial operará a los treinta (30) días hábiles judiciales que establece el art. 223 de la Ley N 3460 segunda parte, contados a partir de la notificación del acto administrativo declarando la lesividad. Es decir, que dentro del plazo de 10 años y 3 años respectivamente prescribe la pretensión del Estado para promover la acción de lesividad y caduca a los 30 días hábiles judiciales de notificado el acto que declara la lesividad.

En Formosa establece plazo de caducidad dentro del plazo de cuatros (4) años contados desde la emisión del acto lesivo y Misiones de ciento ochenta (180) días contados a partir de la fecha en que se dicta el acto que declara la lesividad; el Chaco dentro de los 60 días de dictado el acto que declara la lesividad y otras establecen que la acción de lesividad se interpondrá dentro del plazo de prescripción del derecho material como el régimen federal.

\section{Procedimiento contencioso-administrativo de Corrientes}

\section{1) Régimen Jurídico}

Constitución Provincial

Ley $\mathrm{N}^{\circ}$ 4106: Contencioso Administrativo.

Ley $\mathrm{N}^{\circ}$ 3460: Procedimiento Administrativo.

\section{2) Órgano competente}

${ }^{43}$ Art. 223 segunda parte de la Ley $N^{\circ} 3460$ (mod. Por Decreto Ley 182/01). 
Juzgado de 1era Instancia Contenciosa Administrativa -Ley $\mathrm{N}^{\circ}$ 5846- art. $6^{\circ}$ y $7^{\circ}$.

\section{3) Acción Procesal Administrativa: (Art. $55^{\circ}$ ss. y cc.)}

a) Acción: acción de plena jurisdicción (ordinaria).

b) Pretensión: pluralidad de pretensiones. Anulación parcial o total del acto lesivo y reconocimiento de los daños y perjuicios.

c) Demandante:

La administración centralizada; poder judicial, legislativo y órganos extra poder a través de Fiscalía de Estado, los órganos descentralizados, autárquicos a través de sus procuradores y/o Fiscalía de Estado y los municipios a través del Servicio Jurídico Permanente respectivo.

d) Preparación de la acción:

No se aplica el procedimiento preparatorio de las acciones judiciales (arts. 48 y 54 ss. y cc. de la Ley $\mathrm{N}^{\circ} 4106$ ), por no existir la posibilidad del Recurso Facultativo (art. 95), tampoco se exige el agotamiento de la vía administrativa, pero sí previamente el acto declarativo de la lesividad.

e) Demandado:

El administrado y/o la persona (tercero coadyuvante) a quien beneficie el acto ilegitimo declarado lesivo.

O sea que siempre debe existir un beneficiario del acto declarado lesivo.

f) Medidas Precautorias: (art. 23 ss. y cc. Ley $N^{\circ} 4106$ ).

¿Se pueden solicitar medidas precautorias? La ley en su art. 23 expresamente establece la solución cuando afirma: "las partes podrán solicitar al Tribunal..." y la administración como es parte actora lo puede solicitar, pero además expresamente lo establece el art. 24 "la decisión administrativa que motiva la acción o recurso será título bastante para decretar las medidas a que refiere el artículo anterior, cuando lo solicita la administración pública". lesiva?

g) ¿Se puede solicitar la suspensión de la decisión administrativa declarada

No existe impedimento para que se decrete la suspensión de la decisión administrativa declarada lesiva. El art. 17 de la Ley $\mathrm{N}^{\circ} 4106$ establece que el accionante o el recurrente podrán solicitar se decrete la suspensión del acto. 


\section{Chaco}

La Ley $\mathrm{N}^{\circ} 848$, modificado por la Ley $\mathrm{N}^{\circ} 5759$ (art. $1^{\circ}$ ), incorpora la acción de lesividad, a través del juicio de ilegitimidad en el art. 129 de la ley de procedimientos administrativos $\mathrm{N}^{\circ} 1140$.

No establece plazo de prescripción (se aplica el Código Civil y Comercial), si de caducidad de 60 días de dictado el acto declarativo de la lesividad y establece expresamente que no son recurribles.

Se plantea ante la Cámara Contenciosa Administrativa en instancia única y originaria.

\section{Misiones}

Lo establece en la Ley No 3064, art. 22 inc. "e", no prevé plazo de prescripción se aplica el Código Civil y Comercial, sí de caducidad a los ciento ochenta días contados desde la fecha del dictado del acto que declara la lesividad, a través de la acción ordinaria;

Cuando se refiere a indemnización por incumplimiento de un contrato el plazo es de 90 días contados desde que se dicta el acto que declare el daño y autoriza la promoción de la demanda;

Se plantea ante el Superior Tribunal de Justicia, por la acción ordinaria, instancia única y originaria.

\section{Formosa}

La Ley N 584 en su art. 17 inc. e) regula la acción de lesividad.

Se promueve ante el Superior Tribunal de Justicia y por la acción ordinaria, en instancia única y originaria.

\section{En la Nación}

En el orden nacional si bien no existe Código Procesal Administrativo, los arts. 17 y 18 de la Ley $N^{\circ} 19549$ (Procedimientos Administrativos) expresamente regulan la revocación del acto administrativo en sede administrativa y judicial y así surge o aparece la figura de la acción de lesividad como único medio para anular un acto por razones de ilegitimidad.

El plazo de prescripción surge expresamente del art. 27 de la Ley $N^{\circ} 19549$ 
que no determina tiempo en que el Estado o sus entes autárquicos sean parte actora sin perjuicio de lo que corresponda en materia de prescripción.

La caducidad procederá a partir de la declaración de lesividad de acuerdo al art. 25 (90 días hábiles judiciales de notificado el mismo).

Consideramos que donde las legislaciones no prevean expresamente la acción de lesividad tienen dos caminos o permiten la revocación en sede administrativa (Santa Fe-Pcia. de Buenos Aires- art. 114, Ley N ${ }^{\circ}$ 7647) o pretorianamente se autoriza la acción de lesividad.

Pero no puede rechazarse la posibilidad de que la administración ocurra ante la jurisdicción para solicitar el retiro de sus propios actos afectados de ilegitimidad, sin violar derechos subjetivos de los administrados.

\section{Conclusiones}

La acción de lesividad sería una herramienta útil para el Estado si la misma es usada como medio idóneo para el retiro de los actos irrevocables en sede administrativa.

Generalmente la administración revoca administrativamente actos que han causado estado, que posteriormente son declarados nulos en sede judicial por violar el inc. e) del art. 101 de la Ley $\mathrm{N}^{\circ} 3460$, con lo cual no sólo subsiste el acto lesivo sino además muchas veces debe indemnizar.

Los Servicios Jurídicos Permanentes del Estado, deberían, previo al dictado de actos administrativos que revoquen otros anteriores que generaron derechos subjetivos, dictaminar la necesidad de iniciar la acción de lesividad y solicitar autorización para iniciarla en virtud del art. 101 inc. e) de la Ley $\mathrm{N}^{\circ} 3460$ por la imposibilidad de hacerlo en sede administrativa, pues cuenta con la medida cautelar prevista en el art. 24 de la Ley $\mathrm{N}^{\circ} 4106$, que si es solicitada al plantear la demanda es automática.

No será necesaria la autorización cuando el Fiscal de Estado lo realice en uso de su autonomía funcional prevista en el art. 175, segunda parte de la Constitución de Corrientes.

La Constitución de Corrientes en su art. 27 declara la nulidad de las normas generales, concretos, formales o materiales que impongan limitaciones a las garantías (seguridad jurídica de los administrados y estabilidad de los actos administrativos) consagradas por la Constitución Nacional o Provincial y otorga 
el derechos de accionar contra quienes los ponen en ejecución, sin perjuicio de la reclamación de la inconstitucionalidad de la norma que retira en sede administrativa el supuesto acto ilegitimo o lesivo.

La Ley $\mathrm{N}^{\mathrm{o}} 3460$, art. 101 inc. e) prohíbe que los actos contengan disposiciones que vulneren el principio de irrevocabilidad del acto administrativo en la forma establecida en la ley (art. 183 y 184).

En la Provincia de Corrientes, se han revocados actos perfectos, violando el principio de irrevocabilidad de los actos administrativos, en algunos casos a través de normas de carácter general como el Decreto-Ley No 1/99-art. 10 (cesantías en masa); Decreto-Ley $\mathrm{N}^{\circ} 192 / 02$ y otras a través de actos administrativos concretos (cesantías de funcionarios del Poder legislativo).

\section{Bibliografía}

Aguilar Andrade Juan Pablo. Apuntes sobre la Acción de Lesividad, Revista de Derecho Administrativo, Ecuador, 11 de noviembre de 2009.

Botassi, Carlos A. Ley de Procedimiento Administrativo de la Provincia de Buenos Aires, LEP, La Plata, 1988.

Bustelo, Ernesto N. Estudio de Derecho Administrativo, IX, Ediciones Dike. 2009.

Canda Fabián Omar. Suspensión de los Efectos del Acto Administrativo: Medida Cautelar por excelencia del procedimiento administrativo, Abeledo Perrot, 2010.

Cassagne, Juan Carlos. Acto Administrativo, Abeledo Perrot, 1978.

Cassagne, Juan Carlos. Derecho Administrativo, Tomo II, Editora Abeledo Perrot.

Comadira, Julio R. Procedimientos Administrativos. Ley nacional de procedimientos administrativos, anotada y comentada, Tomo I, La Ley, Buenos Aires, 2002, p. 344 y ss.

Comadira, Julio R. Anulación de oficio del acto administrativo, la denominada cosa juzgada administrativa. Buenos Aires, Astrea, 1981.

Diez, Manuel María. Derecho Procesal Administrativo, Editorial Plus Ultra, 1996.

Diez, Manuel María. Tratado de derecho Administrativo, T. IV, Plus Ultra, 1972. Estrada. La revocación por ilegitimidad del acto administrativo irregular, (LL, 
1976-D-820).

Gordillo. "Tratado de Derecho Administrativo". En: Tratado, T. III, p. VI-17. Hutchinson Tomás. Ley Nacional de Procedimientos Administrativos. Comentada. T. I, Editorial Astrea, 1985.

Hutchinson Tomás. Derecho Procesal Administrativo. T. III, Rubinzal-Culzoni, año 2009.

Montezanti. Suspensión del Acto Administrativo. Astrea, 2009.

Luis Eduardo Rey Vázquez. La potestad revocatoria de la administración por razones de ilegitimidad. Análisis a la luz de la doctrina y jurisprudencia argentina. Revista Digital de Derecho Administrativo Venezolano ${ }^{\circ}$ 6/15.

Revidatti Sassón. Procedimiento Administrativo de la Provincia de Corrientes, Ley N ${ }^{0}$ 3460, Comentada, Cícero Ediciones, Corrientes, 1987.

Revidatti Gustavo Adolfo. Lo Contencioso Administrativo en la Provincia de Corrientes, Ley N ${ }^{\circ}$ 4106, Comentada. Cícero Ediciones, Corrientes, 1987. Revidatti Gustavo Adolfo. Derecho Administrativo. Edit. Fundación de Derecho Administrativo, 1985.

Sassón-Saiach. Derecho Administrativo. Editora Intercontinental, 1995. 